\title{
Residual Stress Measurements in Vintage LPG Pressure Vessel Welds, via Neutron Diffraction
}

\author{
Kaan Sozen ${ }^{1}$, Anna Paradowska ${ }^{2,1}$ a Mark Reid $^{2}$, Roger Griffins ${ }^{3}$, John Daniels ${ }^{1}$ \\ ${ }^{1}$ UNSW, Sydney, NSW 2052, Australia \\ ${ }^{2}$ ANSTO, Australian Centre for Neutron Scattering, Lucas Heights, NSW 2234, Australia \\ ${ }^{3}$ WTIA, Unit 50, 8 Avenue of the Americans, Newington NSW 2127, Australia
}

aTel: +61 (3)9719 3372 E-mail: anp@ansto.gov.au

\begin{abstract}
Keywords: Welding, Residual Stress, Neutron Diffraction, Pressure Vessel, Submerged Arc, Liquid Petroleum Gas (LPG)
\end{abstract}

\begin{abstract}
Systems in power, petrochemical and refinery plants are subject to innumerable degradation mechanisms. Welds are the critical regions in such components. The focus of this project is on Liquid Petroleum Gas (LPG) storage vessels manufactured for Australian refineries in the 1960s. Residual stresses were measured in seam and circumferential welds extracted from the vessels. The aim of this project is to measure the residual stress storage vessel. This data will be used to engineer a procedure to repair the vintage steel plates of the pressure vessels with modern consumables and welding techniques.
\end{abstract}

\section{Introduction}

Residual stresses influence damaging mechanisms including; crack initiation and propagation, fatigue, creep, corrosion, stress corrosion cracking (SCC) and time to final fracture/failure of the component [1]. The residual stresses generated during welding process can be detrimental to the service life of the component, leading to premature and unexpected failure [2-6].

Until recently, the measurement of residual stresses in thick welded components was not practically feasible using non-destructive techniques. Conventionally, the residual stress in welded components was assumed to be equal to the yield of the material [8]. As many pressure vessels and similar components manufactured in the early to mid-twentieth century are still in service, it is important to measure these stresses, and in turn see how their actual values are similar or diverge from this assumption. Furthermore, it is important to understand how modern welding techniques can be employed, and how these repairs influence the remaining service life of the component.

There is a unique opportunity to have access to heritage steel from pressure vessels that were manufactured by the Australian pressure vessel industry in the 1960s. Furthermore, these vessels have been subject both thermal and pressure cycling over the past 50 years. Residual stress measurements in circumferential welded sections and seam welded sections were analysed, using neutron diffraction at the Australian Nuclear Science and Technology Organisation (ANSTO), using the KOWARI strain scanner. Due to the widespread use of aging pressure vessels around Australia and around the world, developing a clear understanding of the impacts of residual stress distributions is an important problem, and should contribute greatly to projected lifetimes of the pressure vessels in question.

\section{Experimental Procedure}

The GS9 pressure vessel was constructed in the 1960s with $29 \mathrm{~mm}$ steel plate of B58A material. 11 plates were used for the body and 4 for the semi-elliptical heads. Plates were formed using a brake press, and welded using submerged arc welding. The seam and circumferential welds were not stress relieved by post weld heat treatment, however hydrostatic testing was employed in their manufacture. 
The pressure vessels were designed for a pressure of 250 Psi, and hydrostatically tested to 425 Psi (being $40 \%$ and $67 \%$ of yield).

Circumferential and seam welds were sectioned from the (Table 1: Test certificate material properties of parent metal) to final plate dimensions were $500 \times 400 \times 29 \mathrm{~mm}^{3}$. This geometry was chosen to preserve the residual stress field in the weld at the centre of the plate. A stress free sample $\left(\mathrm{d}_{0, \mathrm{hkl}}\right)$, was EDM cut from the cross section of the circumferential weld. The stress free reference sample was used to calculate the lattice distortion in the seam and circumferential samples, and in turn calculate the residual stress in these regions.

Table 1 - Test certificate composition and material properties of B58A (1965)

\begin{tabular}{|c|r|r|r|r|r|r|r|}
\hline & $\begin{array}{c}\text { Yield } \\
{[\mathrm{MPa}]}\end{array}$ & $\begin{array}{c}\text { UTS } \\
{[\mathrm{MPa}]}\end{array}$ & $\mathrm{El} \%$ & $\mathrm{C} \%$ & $\mathrm{P} \%$ & $\mathrm{Mn} \%$ & $\mathrm{~S} \%$ \\
\hline $\mathrm{A} 1596$ & 227 & 474 & 25 & 0.25 & 0.042 & 0.62 & 0.047 \\
\hline
\end{tabular}

\section{Neutron Diffraction}

Neutron diffraction was used to measure the residual stresses in the welded samples. Experiments were conducted at Australian Nuclear Science and Technology Organisation (ANSTO), using the KOWARI strain scanner [10]. The nominal gauge volume was $5 \times 5 \times 5 \mathrm{~mm}^{3}$, and 62 points were mapped individually for the circumferential and seam welds, in the longitudinal, transverse and normal directions. An exposure time of 300 seconds per measurement point was used. Neutrons with wavelength $1.67 \AA$ were focussed using the Si (400) double focussing monochromator. Detector angle $(2 \theta)$, was set to $90^{\circ}$, corresponding to $\alpha$-Fe (211) diffraction peak.

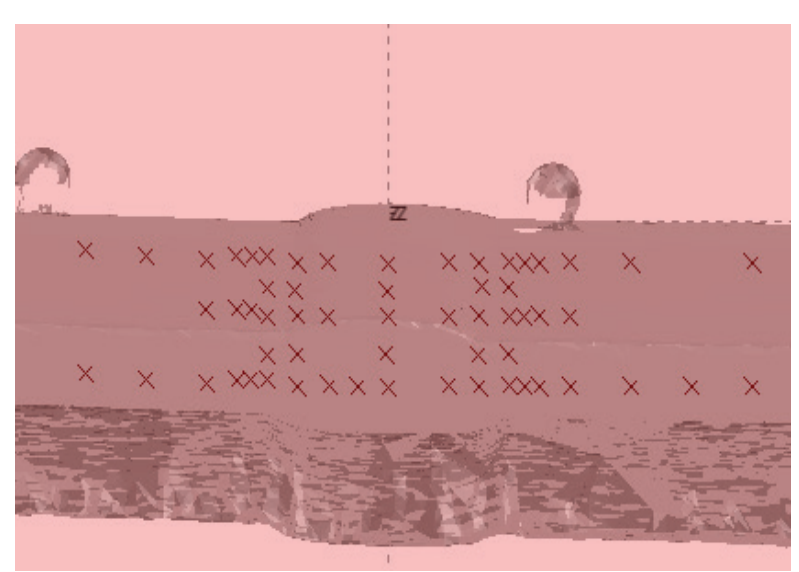

Figure 1 - SScans longitudinal simulation scan of seam weld specimen (62 points)

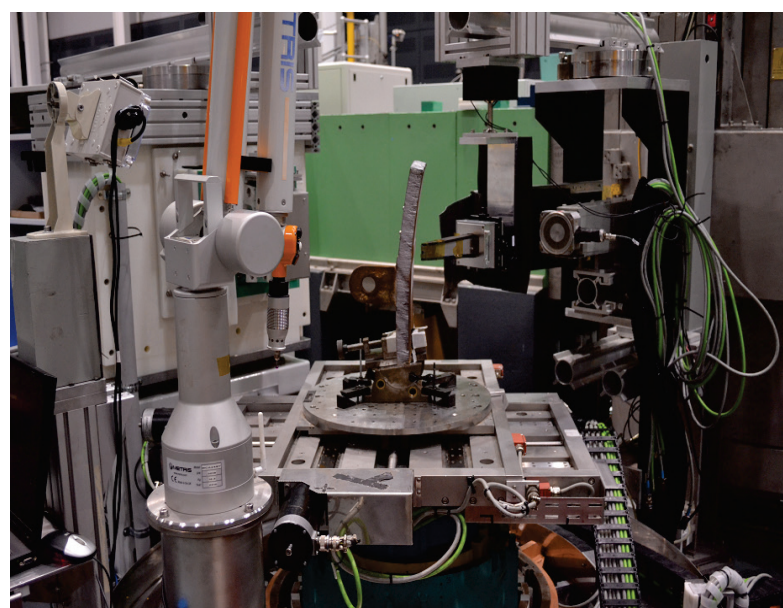

Figure 2 - Neutron Diffraction measurements of seam weld section, using KOWARI strain scanner at ANSTO 


\section{Results and Discussion}

Figure 3 and Figure 4 show an etched macroscopic cross section of the circumferential and seam welds. The images showed that the vessels were welded with a total of 4 passes for each weld type. The first pass was from the inside. Through the measurement of the size of the weld cap and respective heat affected zones, the inside weld had a greater heat input with respect to the outside.

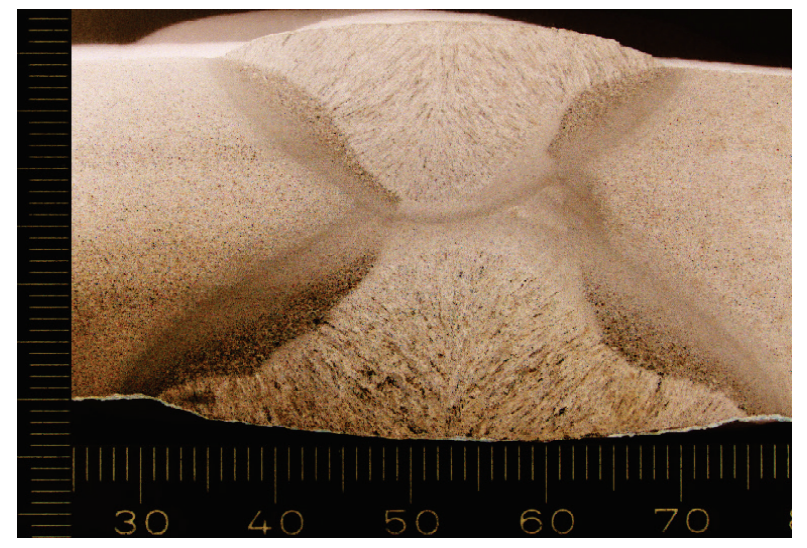

Figure 2 - Seam weld cross section microstructure (Inside of vessel is bottom of image)

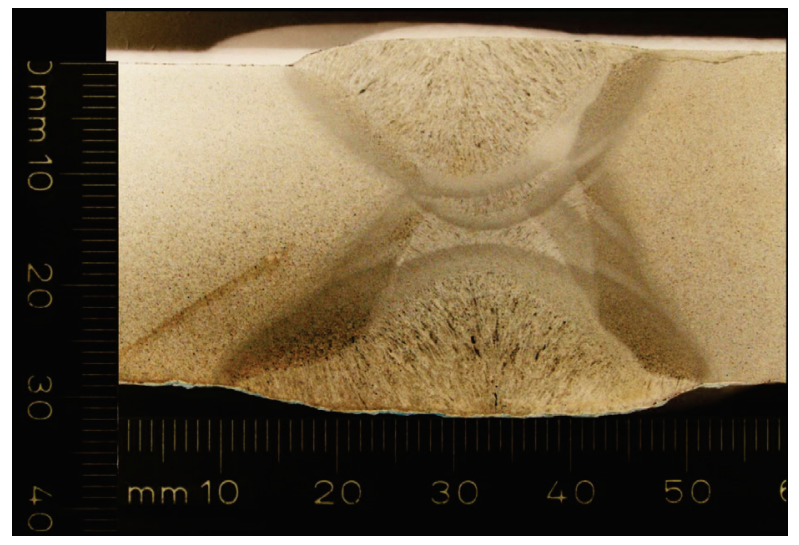

Figure 1 - Circumferential weld cross section microstructure (Inside of vessel is bottom of image)

Figures 5-8, below, show the longitudinal, transverse and normal residual stresses, at the center of the welds and $20 \mathrm{~mm}$ either side, for the circumferential and seam welds. Results showed that for both the welded samples, the maximum stresses were lower than the value used to calculate the critical crack size of $4 \mathrm{~mm}$ by Moss in 1993 [7]. The seam weld has a normalized stress of up to 50\% of the yield stress of the material, and the circumferential weld was larger reaching up to $90 \%$.

For both welds, stresses in the longitudinal direction were tensile and dominant, with transverse stresses also predominantly tensile. The stresses in the radial direction were found to be compressive and low in magnitude. The magnitude of tensile stresses, are greater in the circumferential weld than the seam weld. Historic reports indicate that plates were formed into circular sections and seam welded first, and after the 11 sections of the body have been fabricated, they were circumferentially welded together [7]. This could be a reason to why circumferential weld residual stresses are greater than those seen in the seam welds. 


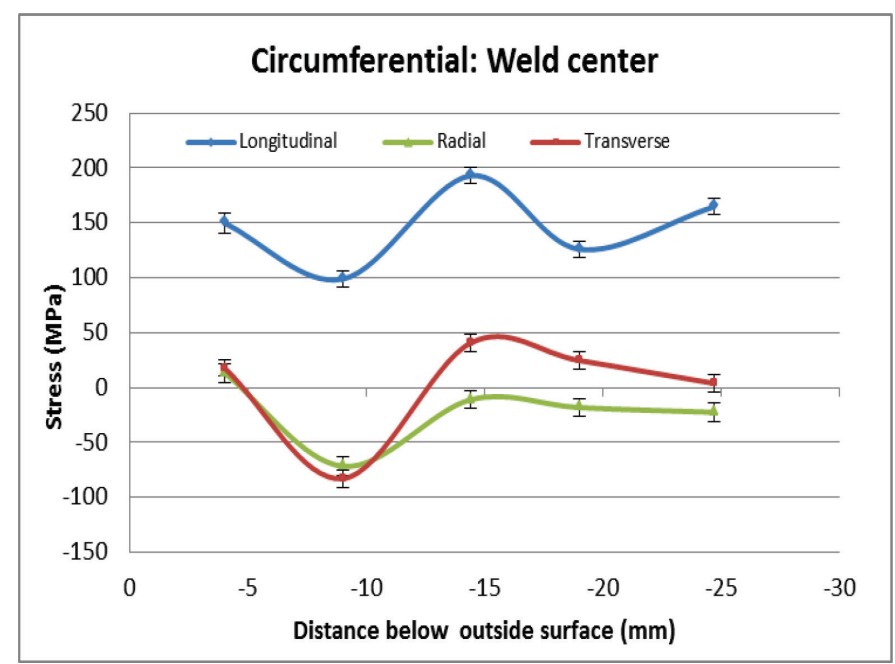

Figure 5 - Residual Stress at circumferential weld centre

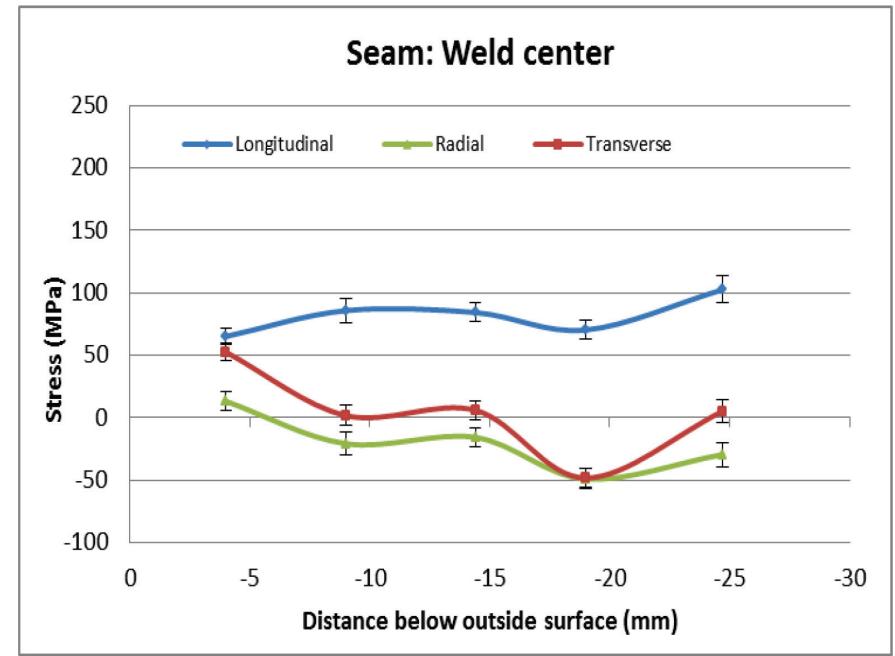

Figure 3- Residual Stress at seam weld centre

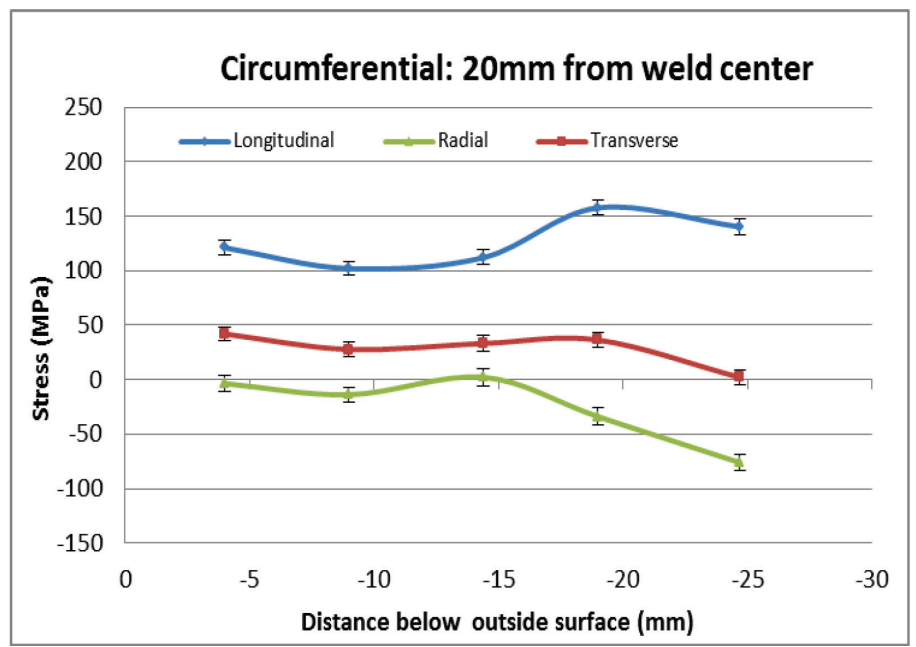

Figure x4-Residual Stress at the toe, $20 \mathrm{~mm}$ from circumferential weld centre 


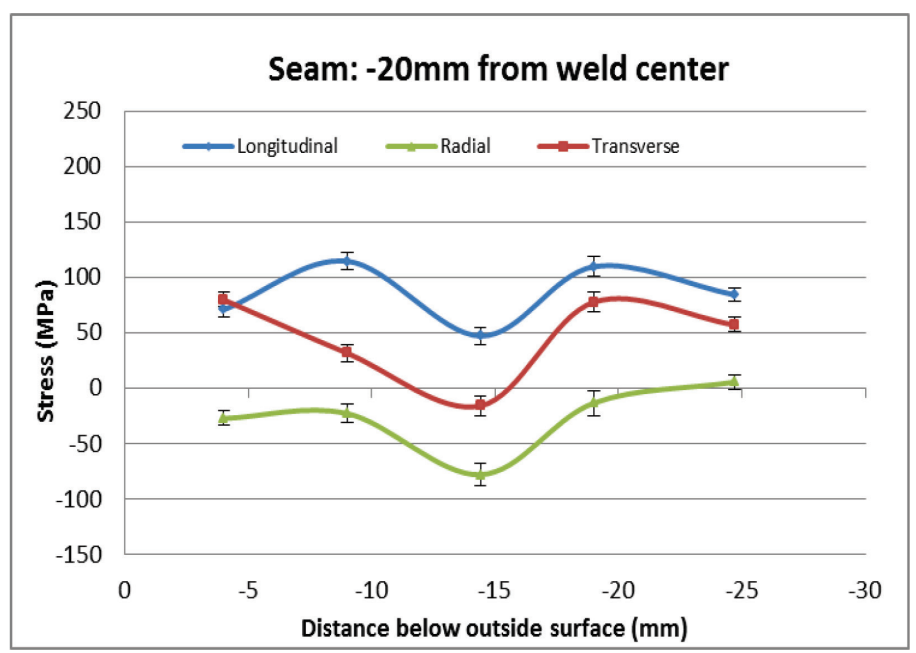

Figure 5- Residual Stress at the toe, -20mm from seam weld centre

Future work:

The above results will aid in the process to engineer a new repair procedure for the LPG pressure vessels, and other vessels manufactured using similar manufacturing practices. An incorrect welding procedure can induce severe undesirable stresses into components. A procedure must be designed to induce desirable stresses into the pressure vessels, to in turn not affect the remaining life time, and allow them to operate in a reliable and safe manner. A repair will be conducted on the inside of both circumferential and seam welded sections, and residual stresses generated through the repair procedure will be compared to the above data. A finite element model will be created for both cases to verify the results obtained through neutron diffraction.

\section{Conclusions}

Neutron diffraction measurements were successfully performed on the thick welded section extracted from the vintage LPG pressure vessel. The important results of this experimental study were:

- Residual stress distributions in the vessels are below the yield stress of the steel material.

- The magnitude of the tensile residual stresses were greater in the circumferential welds, particularly in the longitudinal direction.

- The stresses in the transverse direction were mainly tensile for both specimens, however stresses in the radial direction were found to be compressive and low in magnitude.

- The longitudinal stress in the center of the seam weld was around $50 \%$ of yield.

- The longitudinal stress in the center of the circumferential weld was close to $90 \%$ of yield.

Collected information will provide valuable information for the fitness-for-service assessment, in particular the critical crack size and potential repair procedure in the near future.

\section{Acknowledgement}

This work was conducted with the assistance of an Australian Nuclear Science and Technology Organisation (ANSTO) facilities access award. We are also grateful to the WTIA for providing access to the vintage steel components. 


\section{References}

[1] M. T. Hutchings, Withers.P.J, T. M. Holden, and T. Lorentzen, "Introduction to characterization of residual stress by neutron diffraction,” Mater. Today, 2005, 8: 57. http://dx.doi.org/10.1016/S1369-7021(05)00849-7

[2] P. J. Withers and H. K. D. H. Bhadeshia, "Residual stress Part 1 - Measurement techniques," 2001, Materials Science and Technology.17:355-365. http://dx.doi.org/10.1179/026708301101509980

[3] Alipooramirabad H, Paradowska A, Ghomashchi R, Kotousov A, Reid M. Quantification of residual stresses in multi-pass welds using neutron diffraction. Journal of materials processing technology. 2015;226:40-9. http://dx.doi.org/10.1016/j.jmatprotec.2015.07.002

[4] Balasubramanian V, Guha B. Effect of welding processes on toe cracking behaviour of pressure vessel grade steel. Engineering Failure Analysis. 2004;11:575-87. http://dx.doi.org/10.1016/j.engfailanal.2003.09.005

[5] V. Pearce and V. M. Linton, "Neutron diffraction measurement of residual stress in high strength, highly restrained, thick section steel welds," Phys. B Condens. Matter. 2006, 385386: 590-593.

[6] A.M. Paradowska, J.W.H. Price, T.R. Finlayson, R.B. Rogge, R.L. Donaberger, R. Blevins, R. Ibrahim, Comparison of Neutron Diffraction Residual Stress Measurements of Steel Butt Welds with Current Fitness-For-Purpose Assessments, Transaction of the ASME - Journal of Pressure Vessel Technology, 2010, 132: 051503: 1-7

[7] C. J. Moss, "Investigation of the Structural Integrity of Eight LPG Bullets", ANSTO Report, 1993.

[8] T. Temperatures and W. R. Stresses, "PVP2007-26544 in Ferritic Steels,", 2007,949-956.

[9] J.A. James, L. Edwards, Application of robot kinematics methods to the simulation and control of neutron beam line positioning systems. Nuclear Instruments and Methods in Physics Research A., 2007, 571:709-718. http://dx.doi.org/10.1016/j.nima.2006.11.033

[10] A.M. Paradowska, C Shen, N Larkin, H Li, Z Pan, M Law, Residual stress measurements of welds made with a Tandem Gas Metal Arc Welding (T-GMAW) weld technique, Powder Diffraction, 2014, 29 (S1) 2014 24-27 